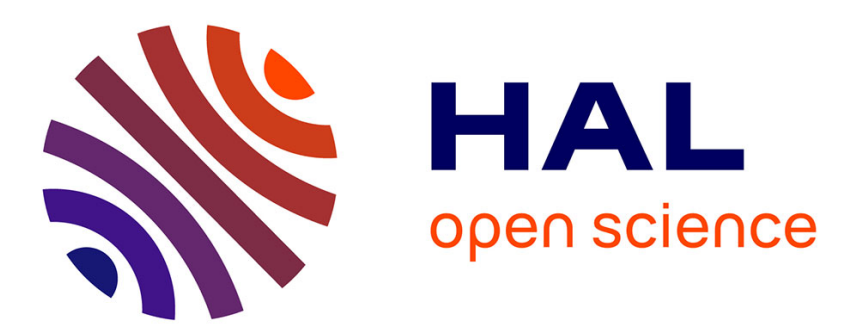

\title{
Experimental evidence for deterministic chaos in electrochemical deposition
}

\author{
Françoise Argoul, A. Arneodo
}

\section{To cite this version:}

Françoise Argoul, A. Arneodo. Experimental evidence for deterministic chaos in electrochemical deposition. Journal de Physique, 1990, 51 (21), pp.2477-2487. 10.1051/jphys:0199000510210247700 . jpa-00212545

\section{HAL Id: jpa-00212545 https://hal.science/jpa-00212545}

Submitted on 1 Jan 1990

HAL is a multi-disciplinary open access archive for the deposit and dissemination of scientific research documents, whether they are published or not. The documents may come from teaching and research institutions in France or abroad, or from public or private research centers.
L'archive ouverte pluridisciplinaire HAL, est destinée au dépôt et à la diffusion de documents scientifiques de niveau recherche, publiés ou non, émanant des établissements d'enseignement et de recherche français ou étrangers, des laboratoires publics ou privés. 
Classification

Physics Abstracts

$61.50 \mathrm{C}-68.70-05.45$

\title{
Experimental evidence for deterministic chaos in electrochemical deposition
}

\author{
F. Argoul (*) and A. Arneodo (*) \\ Centre de Recherche Paul Pascal, Avenue Schweitzer, 33600 Pessac, France
}

(Received 22 May 1990, revised 6 July 1990, accepted 18 July 1990)

\begin{abstract}
Résumé. - Nous présentons ici les résultats d'une étude expérimentale du processus d'électrodéposition de zinc en milieu aqueux bidimensionnel. Pendant le processus de croissance (à courant constant), l'impédance de la cellule électrochimique est mesurée, ce qui permet une analyse simultanée de la complexité géométrique des agrégats et de la dynamique qui gouverne la formation de ces dépôts métalliques. Les régimes étudiés sont intermédiaires entre des croissances métalliques de nature dendritique et des croissances plus désordonnées similaires aux agrégats fractals engendrés par simulation numérique de modèle d'agrégation limitée par la diffusion de Witten et Sander (DLA model). Les enregistrements correspondants mettent en évidence un comportement oscillatoire de l'impédance du milieu électrolytique : ces oscillations peuvent être périodiques comme non périodiques. L'étude de ces dynamiques complexes à l'aide des techniques issues de la théorie des systèmes dynamiques apporte une première évidence expérimentale du caractère chaotique déterministe de ces phénomènes de structuration d'interface. L'observation de bifurcations de doublement de période, de portraits de phase aux allures d'attracteurs étranges, de coupes de Poincaré bien définies et d'applications de l'intervalle en forme de cloche est la signature d'une dynamique à faible nombre de degrés de liberté. L'étude dynamique de régimes encore plus complexes observés dans la limite DLA s'avère être un challenge expérimental des plus prometteurs.
\end{abstract}

\begin{abstract}
We report an experimental study of the statics and dynamics of electrodeposition of zinc in an aqueous medium, in the intermediate regime between dendritic and DLA-like metallic clusters. During the growth process, periodic and nonperiodic oscillations of the voltage are recorded under constant applied current intensity. Period-doubling bifurcations are identified. Analysis of the data in terms of phase portraits, Poincare maps and 1-D maps shows that the fractal geometry of these electrochemical deposits is the signature of a low-dimensional deterministic chaotic dynamics which displays sensitivity to initial conditions. The study of the apparently more complex dynamics recorded in the DLA limit is a very promising experimental challenge.
\end{abstract}

\section{Introduction.}

In recent years, diffusion-limited growth phenomena have been the subject of increasing theoretical and experimental interest [1]. In particular, much effort has been devoted to

$\left(^{*}\right)$ Present address : Department of Physics and the Center for Nonlinear Dynamics, University of Texas, Austin, Texas 78712, U.S.A. 
establishing the relationship between the cluster geometry and growth mechanisms. In Laplacian pattern forming systems, the motion of interfaces can lead to very complex, highly ramified patterns [1]. In the early eighties, Witten and Sander [2] proposed the diffusionlimited aggregation (DLA) model to account for the nonlocal properties of the diffusion field. Extensive computer investigations [1-3] of this model have produced apparently randomly branched fractal clusters that show a strong resemblance to the arborescent patterns observed in a broad class of experimental situations [1], including electrochemical deposition, viscous fingering, colloïdal aggregation, fracture propagation and dielectric breakdown. Since the pioneering simulations of the DLA model, numerous extensions of the model were considered for various purposes [3], e.g., to incorporate non-zero surface tension [1c, 3-7] or to mimic anisotropic growth [3, 8-16]. The fractal geometry of these aggregates has been analyzed by computational [2, 3, 11, 17-24] and analytical methods [15, 25-28]. But thus far, there has been no dynamical study of diffusion limited growth phenomena in numerical simulations as well as in bench experiments. As a consequence, despite the apparent simplicity of the DLA model, there is still no rigourous theory for diffusion-controlled growth. Many important questions remain unanswered; in particular, it is still an open question whether the fractal geometry of DLA clusters is a product of the randomness in the growth process [3] or the result of a proliferation of deterministic tip-splitting instabilities [29].

The specific property that distinguishes growth processes from other non-equilibrium spatio-temporal organization phenomena, e.g. pure reaction-diffusion processes or hydrodynamic turbulence, is that their spatial structure (the fossilized aggregate) retains the full memory of their temporal evolution [30]. Thus one can reasonably suspect that the screening effects induced by the fractal geometry irreversibly influence the dynamics of the growth. Because the complexity of the geometry is intricately connected with the dynamical evolution, most attention has been initially focused on the fractal structure of Laplacian aggregates [1-3, 17-22]. But only very recently [23, 24], DLA clusters were shown to be statistically self-similar as generally believed. Moreover, it has been realized that this geometrical self-similarity is intimately related to the nonhomogeneous distribution of the velocity field along the cluster boundary. Thus, the multifractal properties [31] of the growth probability distribution were investigated through the measurement of the generalized fractal dimensions $D_{q}$ and the $f(\alpha)$-spectrum of singularities [30, 32-38]. But the $D_{q}$ and $f(\alpha)$-spectra are, in effect, statistical averages $[24,39,40]$ that do not provide all the information we need to understand the growth of fractal aggregates. What is essentially missing is the local information concerning the spatial distribution of the scaling exponents along the cluster boundary.

As we have pointed out in our previous study of Laplacian growth processes [23, 24, 30], the application of the wavelet transform [39, 41, 42] may eventually result in a more complete understanding of the local scaling properties of fractal aggregates. In fact, as seen through the "wavelet microscope", the self-similarity of the branched geometry of DLA clusters and electrochemical deposits is likely to be the expression of a nonlinear chaotic recursive construction process which accounts for the proliferation of tip-splitting and side-branching instabilities observed during the growth [24]. But thus far, no computer simulation of the DLA model (image processing of electrodeposition clusters) has achieved the necessary size (resolution) to make definite conclusions about the deterministic character of the fractal patterns observed in diffusion-controlled growth.

In this paper, we take advantage of the fact that electrochemical systems can be used to perform a simultaneous analysis of the statics and the dynamics of fractal growing patterns, to provide unambiguous evidence for the existence of spatio-temporal chaos in fractal growth phenomena. Among the various experimental illustrations of fractal pattern formation, electrochemical deposition is currently considered as the paradigm for theoretical studies of 
interfacial growth processes [29]. In fact, by varying the concentration of metal ions, the conductivity of the electrolyte and the applied constant current (or voltage), one can explore different morphologies like dense radial [43], dendritic [44, 45] and DLA-like fractal [23, 24, 45-48] patterns. The competition between the complex reaction kinetics at the interface and the migration process induced by the electric field is likely to be at the origin of these drastic changes in the morphology of the deposits. Here we will limit our analysis to morphologies obtained at small ionic concentration and low current where the diffusion length becomes much larger than the characteristic size of the pattern [29a]. These morphologies are in fact intermediate regimes [49] between well ordered (anisotropic) dendritic patterns and more randomly ramified (isotropic) DLA like fractal aggregates.

\section{Experimental apparatus.}

The experimental configuration consists of two parallel zinc electrodes $(0.25 \mathrm{~mm}$ diam.) separated by a distance of $120 \mathrm{~mm}$ and contained between two rectangular glass plates (width $30 \mathrm{~mm}$ ). The space between the electrodes is filled by capillarity with an aqueous solution of $\mathrm{ZnSO}_{4}\left(0.05 \mathrm{M}<\left[\mathrm{ZnSO}_{4}\right]<0.30 \mathrm{M}\right)$. The electrodeposition is initiated by applying a constant current between the electrodes. The system is illuminated with white light from below and photographed from above with a $35 \mathrm{~mm}$ camera (magnification from $1 \mathrm{x}$ to $10 \mathrm{x}$ ). During the growth we record the voltage signal with a high resolution (16 bits) and high speed A/D board coupled with an external offset and amplifier (low-pass filter, $f_{\mathrm{c}} \sim 10 \mathrm{~Hz}$ ). This signal provides a measurement of the conductivity of the medium (global impedance of the electrochemical cell including electrodes and electrolyte). Since the conductivity is expected to fluctuate as the structures grow on the surface of the cathode [50], the temporal evolution of the voltage across the cell is likely to provide interesting information about the screening effects and selection processes that govern electrochemical deposition [30]. Our experimental set-up is sketched in figure 1.

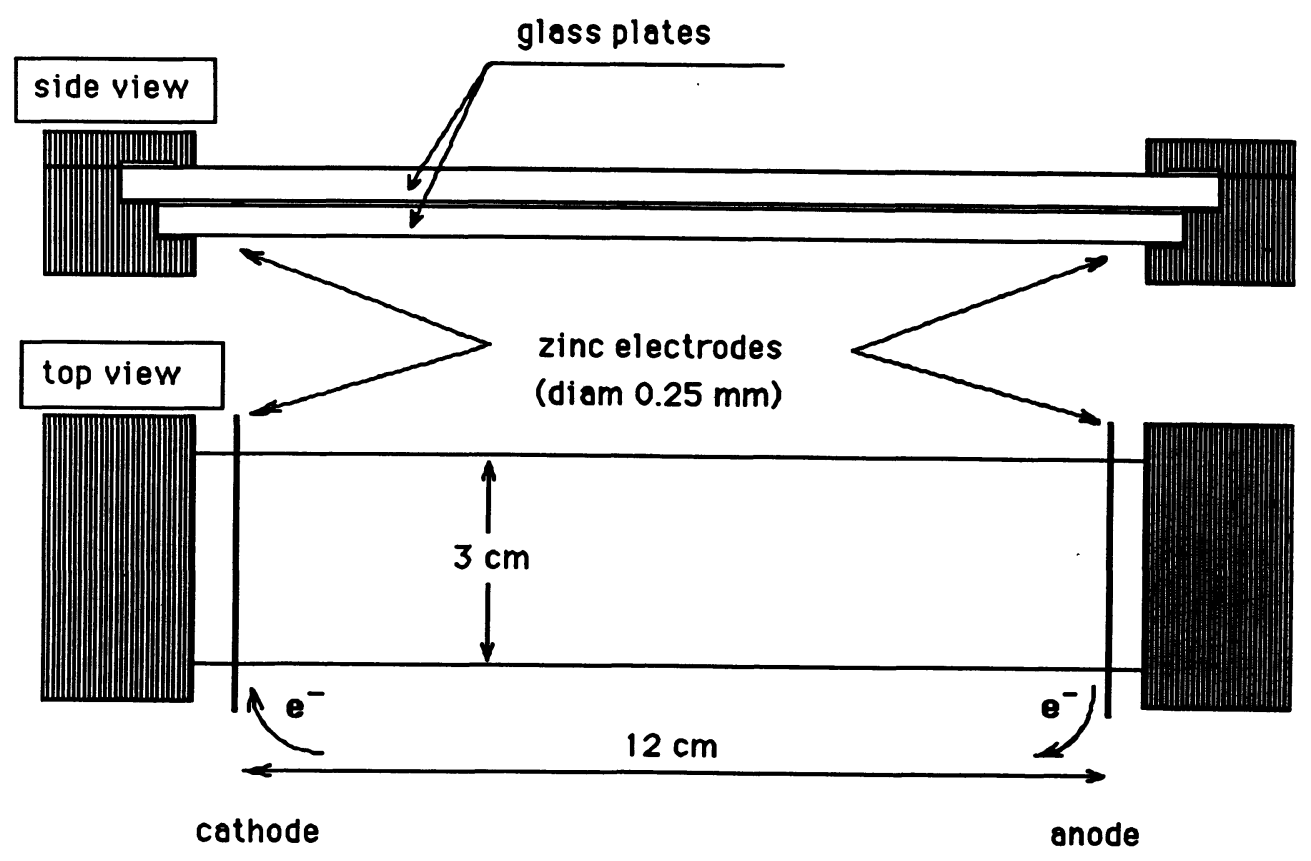

Fig. 1. - Schematic of the linear electrochemical cell. 


\section{Experimental results.}

Our previous analysis $[23,24]$ of fractal electrodeposits strongly suggests that they have a selfsimilar structure $\left(D_{q}=1.63 \pm 0.03, \forall q\right)$ that mimics DLA patterns. In a close neighborhood in the parameter space, conditions can be found where the growth is more directional and where the observed metallic deposits look very much like dendritic patterns [49]. Figure 2 shows several photographs of the early stages of the growth in a regime intermediate between dendritic and DLA growth. After some induction regime observed immediately after turning on the applied current, many zinc trees emerge from the cathode. The initial number of trees is found to depend essentially upon the zinc sulfate concentration, the current intensity $I$ and the cell aspect ratio. The significant feature is that very quickly these trees start competing. Successively, most of them stop growing as they enter in the shade of the surviving trees. At the beginning of the growth, the trees look like spikes. When the selection process is on the way, the surviving trees start to ramify and their width is constantly increasing. Because the diffusion length is larger than the width of the cell, the zinc trees are not only influenced by their immediate neighbourhood, but also by distant trees. Thus, depending on the

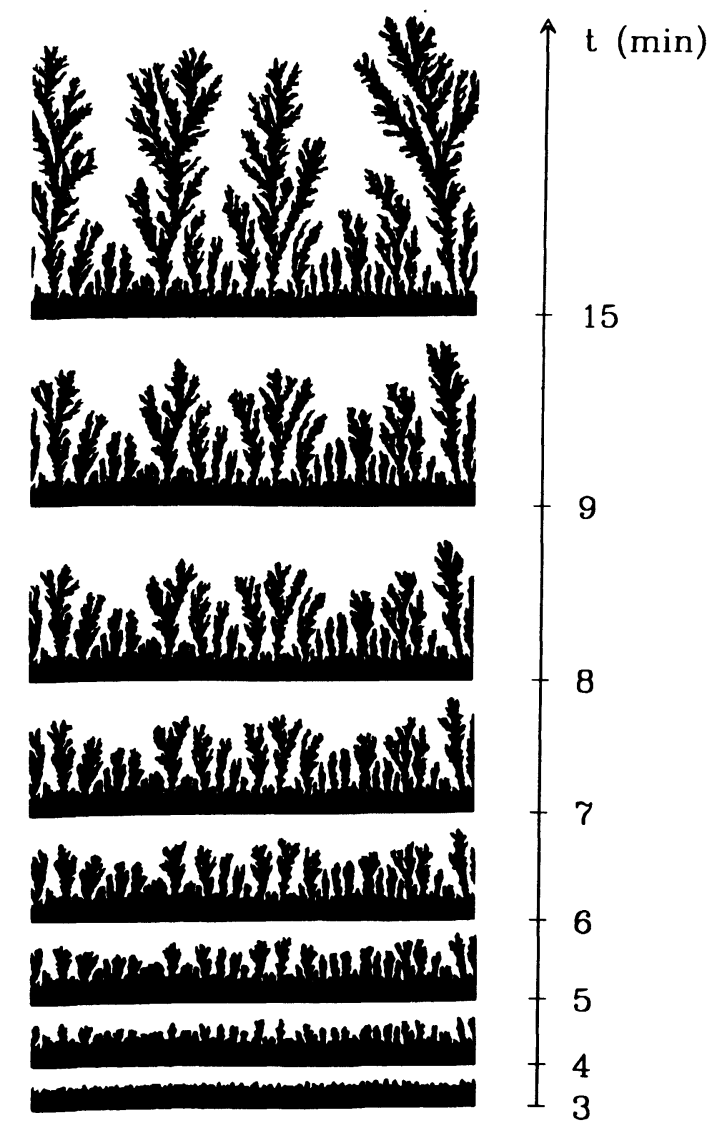

Fig. 2. - Hybrid dendritic-DLA zinc-metal trees (about $15 \mathrm{~mm}$ long after $15 \mathrm{~min}$ of growth) photographed during the early stages of the chemical electrodeposition process. These zinc trees are grown from $0.1 \mathrm{M} \mathrm{ZnSO}_{4}(\mathrm{aq})$ with an applied current of $0.5 \mathrm{~mA}$ (the current density $j$ is equal to $\left.0.21 \mathrm{~A} / \mathrm{dm}^{2}\right)$. 
experimental conditions, cooperative phenomena like the simultaneous extinction of several trees, can be observed. This screening-induced selection process [51] is clearly illustrated in figure 2 where only a few trees survive this «struggle for life", $15 \mathrm{~min}$ after the beginning of the growth. It is noticeable on this figure that the internal structure of these trees is an hybrid disordered dendritic morphology. Let us note at this point that the characteristic size of the surviving trees in the final state in figure 2 remains negligible as compared to the distance between the two electrodes.

In the voltage recording, the induction regime corresponds to an initial sharp decrease, followed by a relatively slow increase of the cell impedance. This rather regular behavior of the voltage is likely to correspond to (i) the formation of the electrochemical double layer [52, 53] at the cathode and anode interfaces (polarization of the electrodes) and (ii) the initial transient regime from a three to a two-dimensional growth process (a rather flat interface starts moving very slowly from the cathode). Apparently, when the voltage exceeds some critical value, oscillations [50] emerge from this quiescent regime as shown in figure 3a. These oscillations can be either periodic (Figs. 3b and 3c) or nonperiodic (Fig. 6a). They are observed simultaneously to the selection process illustrated in the different panels of figure 2 . They actually appear when the instability of the cathode develops into a forest of zinc trees. A
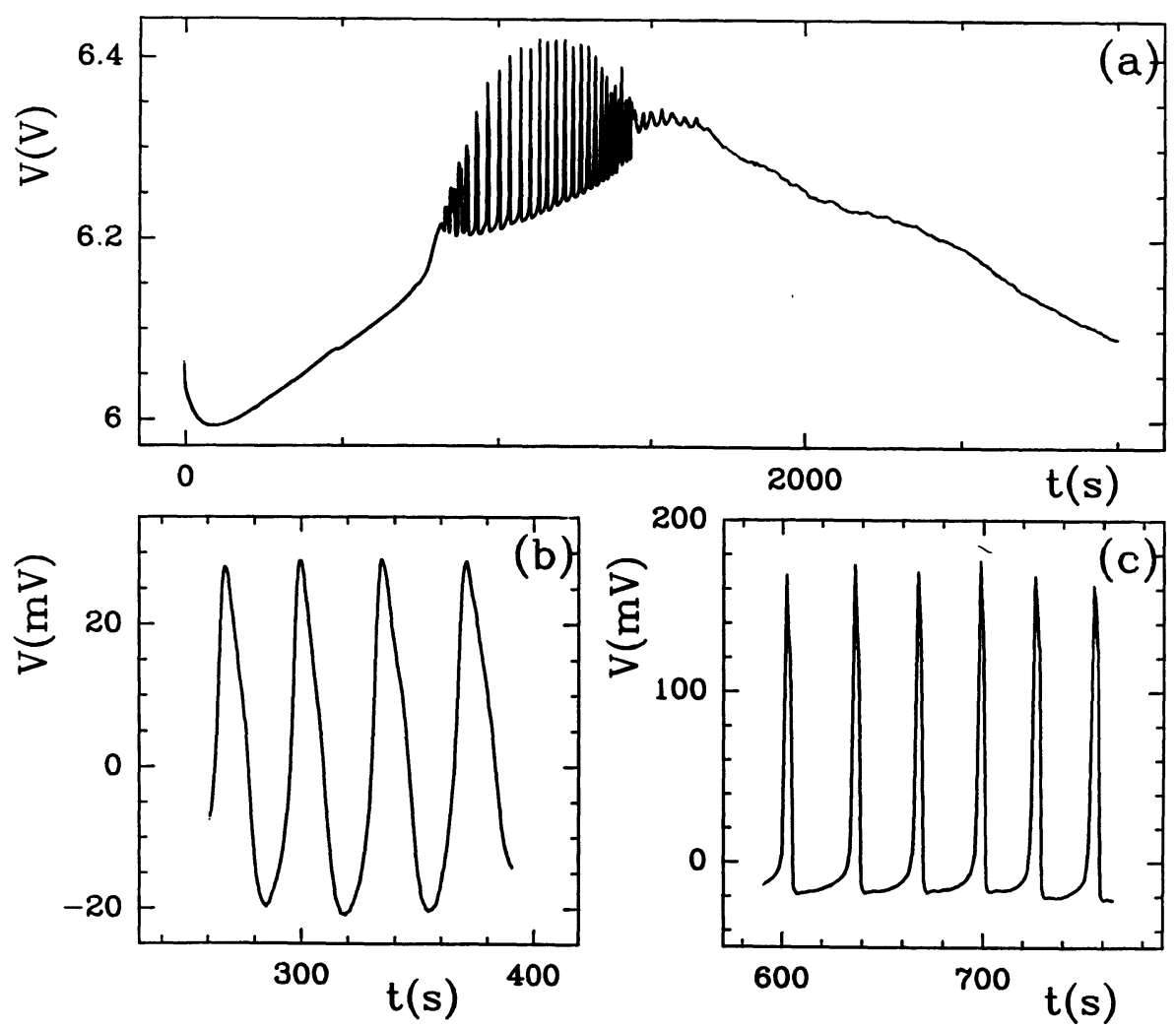

Fig. 3. - Time-series recorded from cell voltage measurements at fixed current intensity. (a) The full time evolution for the parameter values $\left[\mathrm{ZnSO}_{4}\right]=0.25 \mathrm{M}, I=1.5 \mathrm{~mA} \quad\left(j=0.64 \mathrm{~A} / \mathrm{dm}^{2}\right)$. (b) "Quasi " sinusoidal periodic oscillations: $\left[\mathrm{ZnSO}_{4}\right]=0.15 \mathrm{M}, I=0.9 \mathrm{~mA} \quad\left(j=0.382 \mathrm{~A} / \mathrm{dm}^{2}\right)$. (c) Relaxation oscillations : $\left[\mathrm{ZnSO}_{4}\right]=0.25 \mathrm{M}, I=1.5 \mathrm{~mA}\left(j=0.64 \mathrm{~A} / \mathrm{dm}^{2}\right)$. In (b) and (c), the drift in the signal has been removed by Fourier filtering the low frequencies $(f \sim 0)$. 
strong correlation exists between the coherence time of the oscillations and the recursive character of the selection process. Since the interface of the cathode is moving, the amplitude of the oscillating signal displays a slow drift while a shift is detected in its fundamental frequency. These observations indicate that the internal control parameters evolve during the growth. Indeed, this oscillatory regime is a transient phenomenon which turns off as soon as the selection process between the zinc trees is over.

When adjusting the control parameters, in such a way that the electrodeposits display a rather ordered dendritic structure (Fig. 4), the recorded oscillations appear to be coherent over many cycles (Fig. 3). Once the drift inherent to growth processes with moving interface is removed by Fourier filtering the low frequencies $(f \sim 0)$, these oscillations turn out to be periodic. We have observed both « quasi » harmonic oscillations (Fig. 3b) which resemble the oscillations of small amplitude that emerge from a Hopf bifurcation [54], and relaxation oscillations (Fig. 3c) which are current phenomena in non-equilibrium chemical systems [55]. Both these oscillations have approximately the same characteristic frequency $f \sim 25 \mathrm{mHz}$, but the relaxation oscillations provide evidence for enhanced nonlinear interactions between the zinc trees that lead to an abrupt extinction of the growth of the screened trees (sudden death induced by screening). Let us note that the characteristic frequency of the recorded oscillations is at least two orders of magnitude smaller than the characteristic frequency of convective motions that are observed at the growing tips of the zinc trees. This observation

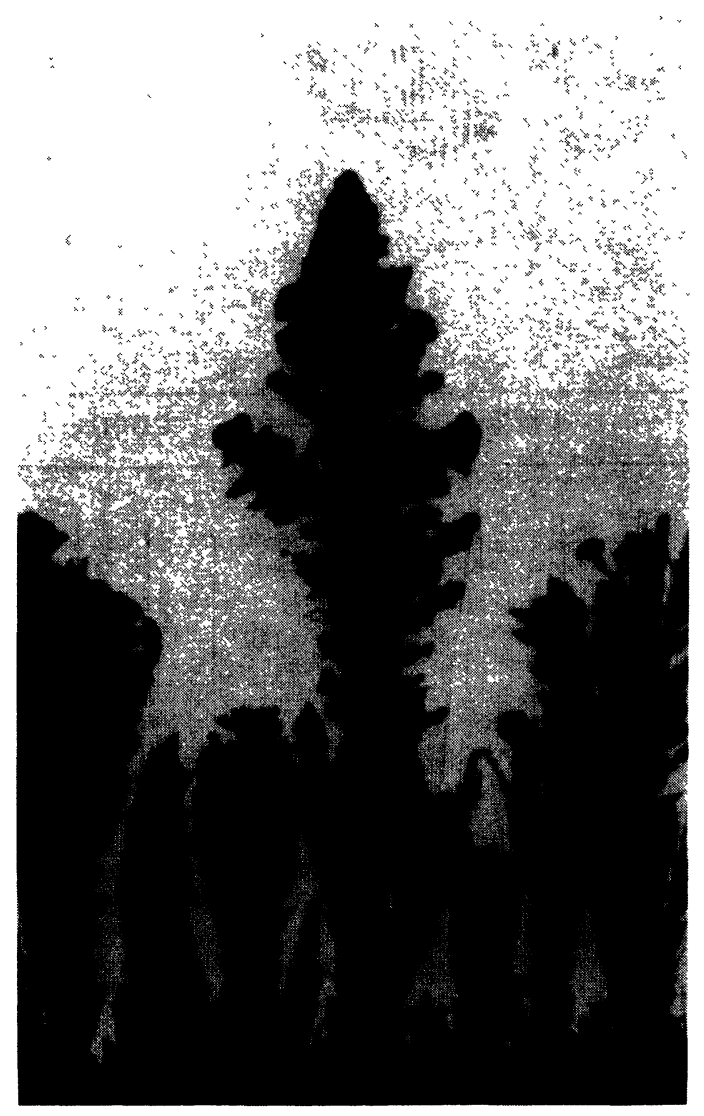

Fig. 4. - Dendritic zinc metal trees photographed during the early stages of the chemical electrodeposition process for the parameter values : $\left[\mathrm{ZnSO}_{4}\right]=0.2 \mathrm{M}, I=2.1 \mathrm{~mA}\left(j=0.89 \mathrm{~A} / \mathrm{dm}^{2}\right)$. 
discards any interpretation of the macroscopic nonlinear selection process in terms of hydrodynamic instabilities.

When moving the system away from the dendritic morphology, toward more disordered highly ramified fractal patterns, period-doubling bifurcations (Fig. 5) are observed as the precursor to chaotic dynamics. In figure 6, we describe a chaotic regime observed simultaneously to the growth of the hybrid dendrite-DLA morphology shown in figure 2 . The nonperiodicity of the recorded time-series is analyzed using well-known techniques such as phase portraits, Poincaré maps and one-dimensional maps [54]. Figure 6b shows a threedimensional phase portrait reconstructed from the time-series of figure 6a using the time delay method [56, 57]. It looks strikingly similar to the phase portraits of strange attractors displayed by low-dimensional dynamical systems [54] (e.g. Rossler's strange attractors). Rather than analyze the phase portrait directly, it is easier to look at the Poincaré section formed by the intersections of the trajectories with a plane approximately normal to the orbits. As shown in figure $6 \mathrm{c}$, the points on the Poincare plane lie to a good approximation along a smooth curve. The fact that the Poincare section is not a scatter of points rules out any stochastic interpretation of these complex oscillations ; moreover it demonstrates the lowdimensional nature of this chaotic state : the orbits lie approximately on a (multifolded) two-
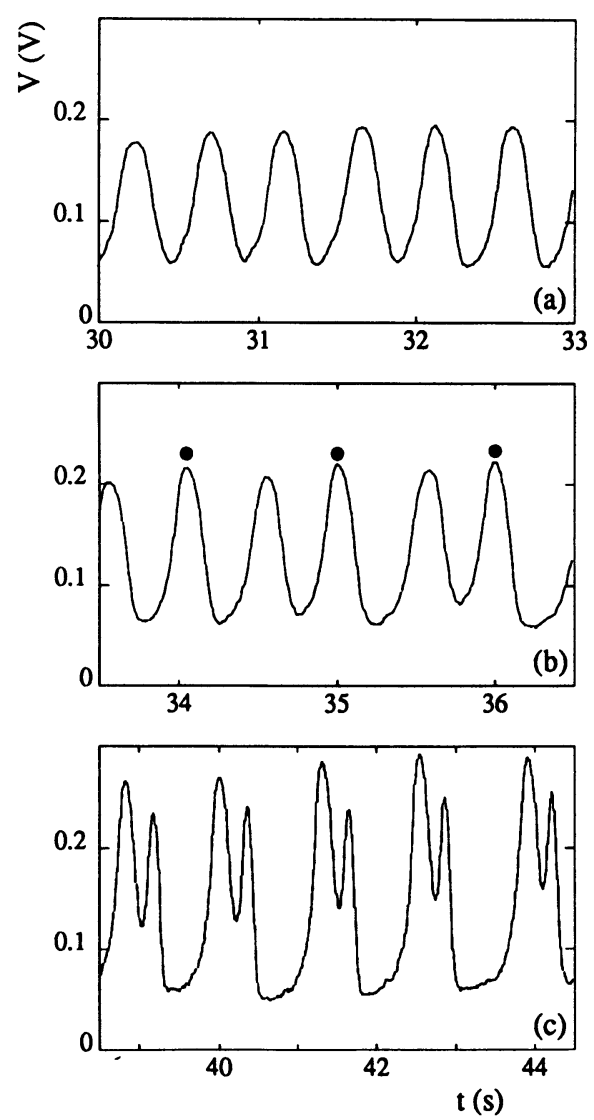

Fig. 5. - Experimental evidence for a period-doubling bifurcation in the electrochemical deposition process for the parameter values corresponding to the dentritic regime shown in figure 4. (a), (b) and (c) represent different stages of the electrochemical deposition process. 

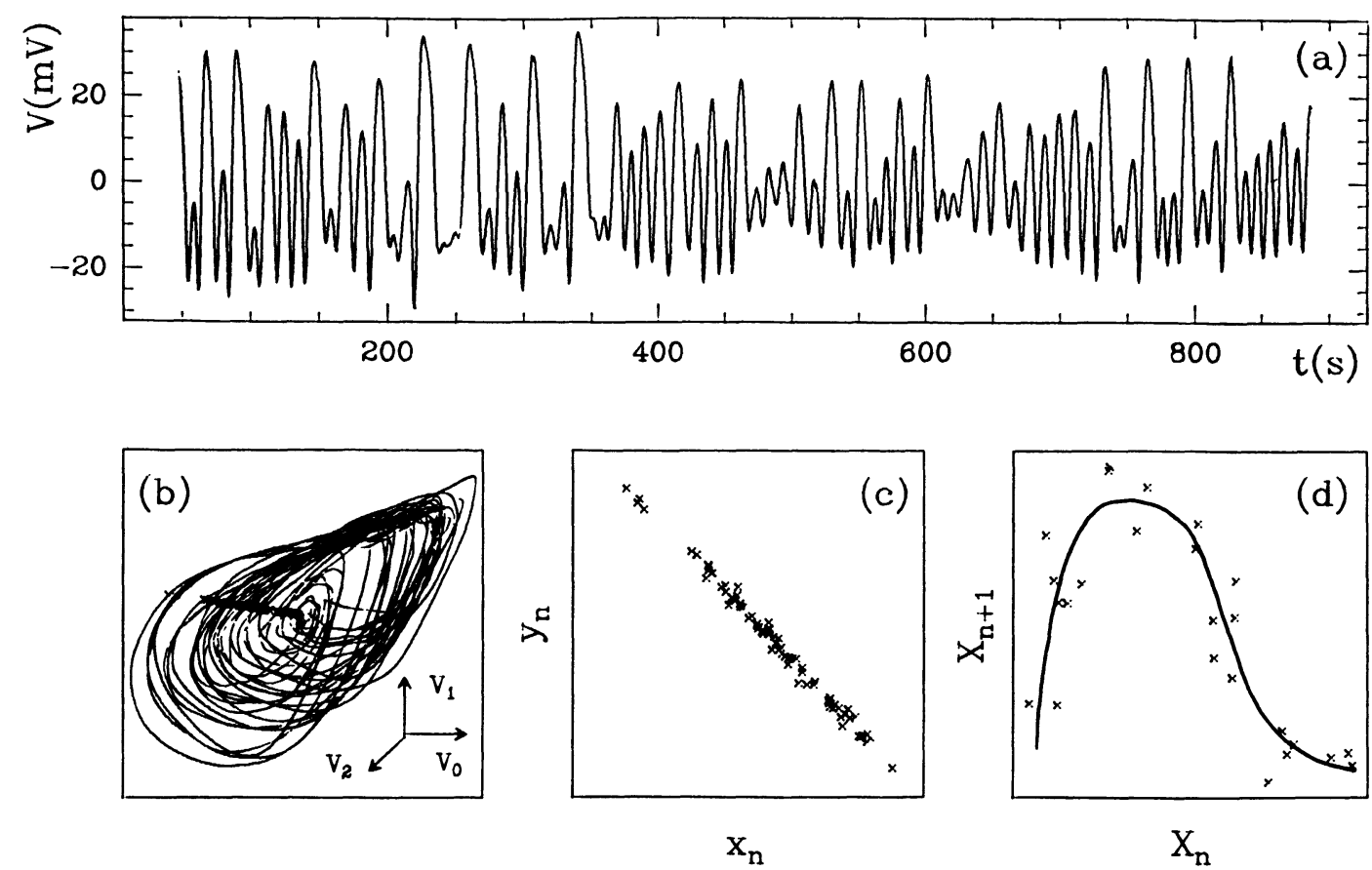

Fig. 6. - A chaotic regime extracted from potential measurement during the screening induced selection process shown in figure 2. (a) The filtered signal $V(t) v s$. time (the drift has been removed by Fourier filtering the low frequencies $(f \sim 0))$; (b) A three-dimensional phase portrait $\left(V_{0}=\right.$ $\left.V(t), V_{1}=V(t+\tau), V_{2}=V(t+2 \tau)\right)$ reconstructed from the time-series in (a) using the time-delay method with $\tau=2.5 \mathrm{~s}$. (c) A Poincaré section constructed by the intersections $\left(x_{n}, y_{n}\right)$ of negatively directed trajectories with the plane passing through the line sketched in (b). (d) A one-dimensional map obtained by plotting as ordered pairs $\left(X_{n}, X_{n+1}\right)$, where $X_{n}=x_{n} \cos \theta+y_{n} \sin \theta$ and $\theta=85^{\circ}$; the hand-drawn curve suggests the existence of a unimodal 1-D map.

dimensional sheet in the phase-space. Further insight into the dynamics can be achieved by constructing a one-dimensional map; a plot of $X_{n+1}$ vs. $X_{n}$ is shown in figure 6d, where $X$ is some coordinate in the Poincaré plane. Within the experimental resolution, the data appear to fall on a smooth curve, indicating that the dynamics is governed by a deterministic law ; for any $X_{n}$, the map gives the value $X_{n+1}$ at the next intersection. The hand-drawn curve suggests the existence of a unimodal 1-D map, the hallmark of deterministic chaos [54, 58]. The dispersion of points around this curve is the consequence of the transitory character of this selection process. The experimental points plotted in figure $6 \mathrm{~d}$ correspond to the initial part of the time series in figure 6a. Further recording displays an overall shift of the 1-D map with a slight decrease of its height, as the consequence of the internal control parameter evolution during the growth. This observation sets a fundamental physical limitation to any noise reducing procedure for decreasing the dispersion of points around the hand-drawn curve in figure 6d. Let us note that the existence of an underlying unimodal 1-D map is indirectly confirmed by the identification of the first steps of the period-doubling cascade [58-60] illustrated in figure 5. A systematic investigation of the routes to chaos in electrochemical deposition will be reported elsewhere. 


\section{Discussion.}

In conclusion, these experimental results supply the first inescapable evidence for the existence of deterministic chaos in electrochemical deposition process. In the present work, we have mainly focused on the nonlinear electrostatic interactions between metallic trees lying in a complex dielectric medium in the early stages of an hybrid disordered dendritic growth. These observations indicate that the selection process between metallic trees is likely to result from the nonlinear interaction of a small number of elementary instabilities.

However, it is clear that considerable further work is needed to understand the intimate relationship between the cluster geometry and the growth mechanism which governs pattern formation. In particular, preliminary experimental results strongly suggest that the dynamics becomes more complex when moving further the electrochemical system towards the disordered highly ramified DLA morphology. Because DLA trees ramify as soon as they emerge from the cathode, it is reasonable to suppose that the screening process between the internal branches of each individual tree will lead to superposed oscillations of higher frequency and smaller amplitude than the low-frequency chaotic oscillations. One may thus suspect a transition to a higher-dimensional turbulent dynamics. Unfortunately, the large impedance of our electrochemical cell results in a high level of noise that requires the use of a low-pass filter $\left(f_{\mathrm{c}} \sim 10 \mathrm{~Hz}\right)$. Therefore, the high frequency sensitivity of our experimental setup needs to be significantly improved in order to address the fundamental issue of the actual degree of complexity of the DLA dynamics.

An alternative to this experimental study is the simulation of DLA in linear geometry solving the Laplace equation with the Green's function method [25, 61, 62]. This method allows us to compute directly the impedance of the cell at each time step. It can thus be used to mimic our voltage recording in the electrochemical system. Experiments and simulations along these lines are currently in progress [63].

\section{Acknowledgments.}

The authors are very grateful to the Centre National des Etudes Spatiales for financial support under contract ( ${ }^{\circ}$ 90/CNES/215).

\section{References}

[1] For reviews see:

(a) LANGer J. S., Rev. Mod. Phys. 52 (1980) 1 ;

(b) Huang S. C. and Glicksman M. E., Acta Metall. 29 (1981) 701 ;

(c) Bensimon D., Kadanoff L. P., Liang S., Shraiman B. I. and Tang C., Rev. Mod. Phys. 58 (1986) 977 ;

(d) LANGer J. S., Chance and Matter, Eds. J. Souletie, J. Vanimenus and R. Stora (NorthHolland, Amsterdam) 1987 ;

(e) Kessler D. A., Koplik J. and Levine H., Adv. Phys. 37 (1988) 255 ;

(f) On Growth and Form: Fractal and Nonfractal Patterns in Physics, Eds. H. E. Stanley and N. Ostrowsky (Martinus Nijhof, Dordrecht) 1986 ;

(g) Fractal in Physics, Eds. L. Pietronero and E. Tosati (North-Holland, Amsterdam) 1986 ;

(h) The Physics of Structure Formation, Eds. W. Guttinger and D. Dangelmayr (Springer-Verlag, Berlin) 1987;

(i) Random Fluctuations and Pattern Growth, Eds. H. E. Stanley and N. Ostrowsky (Kluwer, Dordrecht) 1988 ;

(j) VICSEK T., Fractal Growth Phenomena (World Scientific, Singapore) 1989. 
[2] Witten T. and Sander L. M., Phys. Rev. Lett. 47 (1981) 1400 ; Phys. Rev. B 27 (1983) 5686.

[3] (a) Meakin P., Phase Transitions and Critical Phenomena, Eds. C. Domb and J.-L. Lebowitz (Academic, Orlando) 1988, vol. 12;

(b) Nittmann J. and Stanley H. E., Nature (London) 321 (1986) 663 ; J. Phys. A 20 (1987) L1185;

(c) StANLey H. E., in Ref. [1h], p. 210.

[4] VicSeK T., Phys. Rev. Lett. 53 (1984) 2281 ; Phys. Rev. A 32 (1985) 3084.

[5] Banavar J. R., Kohmoto M. and Roberts J., Phys. Rev. A 33 (1986) 2065.

[6] Meakin P., Family F. and Vicsek T., J. Coll. Int. Sci. 117 (1987) 394.

[7] Tao R., Novotny M. A. and Kaski K., Phys. Rev. A 38 (1988) 1019.

[8] Ball R. C., Brady R. M., Rossi G. and Thompson B. R., Phys. Rev. Lett. 55 (1985) 1406.

[9] Matsushita M. and Kondo H., J. Phys. Soc. Jpn 55 (1986) 2483.

[10] Kertész J. and Vicsek T., J. Phys. A 19 (1986) L257.

[11] Meakin P., Phys. Rev. A 33 (1986) 1984 and 3371 ; Phys. Rev. A 36 (1987) 332.

[12] Family F., Platt D. E. and Vicsek T., J. Phys. A 20 (1987) L1177.

[13] KOLB M., Europhys. Lett. 4 (1987) 85.

[14] Meakin P., Kertész J. and Vicsek T., J. Phys. A 21 (1988) 1271.

[15] Eckmann J. P., Meakin P., Procaccia I. and Zeitak R., Phys. Rev. A 39 (1989) 3185.

[16] Couder Y., Argoul F., Arneodo A., Maurer J. and Rabaud M., Phys. Rev. Lett. A 42 (1990) to appear.

[17] Meakin P., Phys. Rev. A 27 (1983) 1495.

[18] Meakin P. and Wasserman Z. R., Chem. Phys. 91 (1984) 391.

[19] Meakin P. and Sander L. M., Phys. Rev. Lett. 54 (1985) 2053.

[20] Ball R. C. and Brady R. M., J. Phys. A 18 (1985) L809.

[21] Meakin P., Ball R. C., Ramanlal P. and Sander L. M., Phys. Rev. A 35 (1987) 5233.

[22] Meakin P. and Havlin S., Phys. Rev. A 36 (1987) 4428.

[23] Argoul F., Arneodo A., Grasseau G. and Swinney H. L., Phys. Rev. Lett. 61 (1988) 2558.

[24] Argoul F., Arneodo A., Elezgaray J., Grasseau G. and Murenzi R., Phys. Lett. A 135 (1989) 327 and Phys. Rev. A 41 (1990) 5537.

[25] Turkevich L. A. and Scher H., Phys. Rev. Lett. 55 (1985) 1026.

[26] Ball R. C., Physica A 140 (1986) 62.

[27] Halsey T. C., Meakin P. and Procaccia I., Phys. Rev. Lett. 56 (1986) 854.

[28] Matsushita M., Honda K., Toyoki H., Hayakawa Y. and Kondo H., J. Phys. Soc. Jpn 55 (1986) 2618.

[29] (a) SANDER L. M., in Refs. [1g] p. 241 and [1h] p. 257 ;

(b) Sander L. M., Ramanlal P. and Ben Jacob E., Phys. Rev. A 32 (1985) 3160.

[30] Argoul F., Arneodo A., Elezgaray J. and Grasseau G., Quantitative Measures of Complex Dynamical Systems, Eds. N. B. Abraham, A. M. Albano, A. Passamante and P. E. Rapp (Plenum) 1990, p. 433.

[31] Halsey T. C., Jensen M. H., Kadanoff L. P., Procaccia I. and Shraiman B. I., Phys. Rev. $A 33$ (1986) 1141.

[32] Meakin P., Phys. Rev. A 34 (1986) 710 ; 35 (1987) 2234.

[33] Amitrano C., Coniglio A. and Diliberto F., Phys. Rev. Lett. 57 (1986) 1016.

[34] Hayakawa Y., Sato S. and Matsushita M., Phys. Rev. A 36 (1987) 1963.

[35] Lee J. and Stanley H. E., Phys. Rev. Lett. 61 (1988) 2945.

[36] Ramanlal P. and Sander L. M., J. Phys. A 21 (1988) L995.

[37] Ball R. and Blunt M., Phys. Rev. A 39 (1989) 3591.

[38] Lee J., Alstrom P. and Stanley H. E., Phys. Rev. A 39 (1989) 6545.

[39] Arneodo A., Argoul F., Elezgaray J. and Grasseau G., Nonlinear Dynamics, Ed. G. Turchetti (World Scientific, Singapore) 1989, p. 130.

[40] Chhabra A. B., Jensen R. V. and Sreenivasan K. R., Phys. Rev. A 40 (1989) 4593.

[41] Holschneider M., J. Stat. Phys. 50 (1988) 963.

[42] Arneodo A., Grasseau G. and Hoschneider M., Phys. Rev. Lett. 61 (1988) 2281.

[43] Grier D. G., Kessler D. A. and Sander L. M., Phys. Rev. Lett. 59 (1987) 2315. 
[44] Sawada Y., Dougherty A. and Gollub J. P., Phys. Rev. Lett. 56 (1986) 1260.

[45] Grier D., Ben-Jacob E., Clarke R. and SANDer L. M., Phys. Rev. Lett. 56 (1986) 1264.

[46] BRAdY R. M. and BALl R. C., Nature 309 (1984) 225.

[47] Matsushita M., Sano M., Hayakawa Y., Honjo H. and Sawada Y., Phys. Rev. Lett. 53 (1984) 286.

[48] Matsushita M., Hayakawa Y. and Sawada Y., Phys. Rev. A 32 (1985) 3814.

[49] Grier D. G., Allen K., Goldman R. S., Sander L. M. and Clarke R., Phys. Rev. Lett. 64 (1990) 2152.

[50] Suter R. M. and Wong P., Phys. Rev. B 39 (1989) 4536.

[51] Curtis S. A. and Maher J. V., Phys. Rev. Lett. 63 (1989) 2729.

[52] Goodisman J., Electrochemistry: Theoretical Foundations (Wiley, New York) 1987.

[53] HALSEY T. C. and LeiBig M., Electrodeposition and diffusion-limited aggregation, preprint (1989).

[54] (a) GuCKenheimer J. and Holmes P., Nonlinear Oscillations, Dynamical Systems and Bifurcations of Vector Fields (Springer-Verlag, Berlin) 1984 ;

(b) Universality in Chaos, Ed. P. Cvitanovic (Hilger, Bristol) 1984 ;

(c) Chaos, Ed. Hao Bai-Lin (World Scientific, Singapore) 1984 ;

(d) Schuster H. G., Deterministic Chaos (Physik-Verlag, Weinheim) 1984 ;

(e) Bergé P., Pomeau Y. and Vidal C., Order within Chaos (Wiley, New York) 1986.

[55] (a) Nonlinear Phenomena in Chemical Dynamics, Eds. C. Vidal and A. Pacault (Springer-Verlag, Berlin) 1981 ;

(b) Nonequilibrium Dynamics in Chemical Systems, Eds. C. Vidal and A. Pacault (SpringerVerlag, Berlin) 1984.

[56] Packard N. H., Crutchfield J. P., Farmer J. D. and Shaw R. S., Phys. Rev. Lett. 45 (1980) 712.

[57] Takens F., Lect. Notes Math. 898 (1981) 366.

[58] Collet P. and EckmanN J. P., Iterated Maps of an Interval as Dynamical Systems (Birkhauser, Boston) 1980.

[59] Feigenbaum M. J., J. Stat. Phys. 19 (1978) 25 ; 21 (1979) 669.

[60] Coullet P. and Tresser C., J. Phys. Colloq. France 39 (1978) C5 ;

Tresser C. and Coullet P., C. R. Acad. Sci. 287 (1978) 577.

[61] MORItA T., J. Math. Phys. 12 (1971) 1744.

[62] Niemeyer L., Pietronero L. and Wiesman H., Phys. Rev. Lett. 52 (1984) 1033.

[63] Argoul F., Arneodo A., Elezgaray J. and Swinney H. L., Proc. of the NATO Summer School, Growth and Forms : Nonlinear Aspects, Eds. M. Ben Amar, P. Pelce and P. Tabeling (Cargèse) 1990, to appear. 